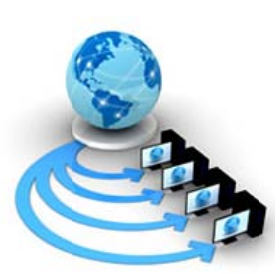

Volume 9, No. 1, January-February 2018

International Journal of Advanced Research in Computer Science

RESEARCH PAPER

\author{
Available Online at www.ijarcs.info
}

\title{
IOT BASED HEALTH CARE SYSTEM FOR HIV ANALYSIS
}

\author{
Sandeep Kaur \\ Assistant Professor, \\ GNDU, RC, Gurdaspur, Punjab, India
}

\begin{abstract}
Diseases are common nowadays and are difficult to detect. Some diseases are life-threatening, and some are normal in nature. Detection and prevention of life-threatening diseases are important. One of the most widely spreading viri is HIV(human immunodeficiency virus). The disease caused by HIV is not curable up till now. This virus can spread to other persons under certain circumstances. The circumstances which make this virus spread are analyzed in this paper. In the proposed paper we conduct an analysis of various HIV infection viruses and system by which this virus spread forward. The database which is present at GenBank is used. The database is online in nature. Internet of things will be used in order to detect the persons who are infected with this virus. The key point in this paper is to use GPS system in order to identify the infected persons and to quarantined them as early as possible.
\end{abstract}

Keywords: HIV, Internet of Things(IoT), a Geographic positioning system(GPS), Genbank.

\section{INTRODUCTION}

HIV is a virus which causes AIDS(Acquired Immune Deficiency Syndrome). This disease directly affects the immune system of the human being. This will cause the humans vulnerable to the various other diseases and infections. HIV is commonly found in the body fluid of the infected person. This means this virus is present in the blood of the infected person. There exist means by which it can be transferred from one person to other. The knowledge of the virus and the mechanism by which it can be transferred is important. Hardware and software devices are required in order to remotely detect the rate at which the disease is spreading. The most important device is sensors.

Sensors are now days commonly used in the medical instruments for monitoring of the health. The network of sensors and other mobile communication instruments are commonly known as IoT(Internet of Things). The Internet of things found its application in medical line which is known as IoT-MD(Internet of things for Medical Instruments). Health system has gained prominence as the chronicle disease is spreading quickly, and there is a stringent need to control the cost associated with the detection and prevention of such diseases. By the use, Information moves quickly, and it will be easy to access also. In IoT-MD system the key parameters of the person will be transferred to the system using a medical device where it is analyzed, and real-time evidence-based medicine system is proposed.

There is a number of applications which are associated with the IoT-MD. The main application describes the ease with which care to the person can be provided right at the patient home. All of the applications are based upon the instruments which are present within the IoT. The tabular representation describes the function of the various instruments which can be used within the IoT-MD.
TABLE I

Describing versatility of the instruments used for the detection of the problems

\begin{tabular}{|c|c|c|c|}
\hline \multicolumn{4}{|c|}{ Instruments } \\
\hline $\begin{array}{l}\text { Important } \\
\text { sign monitor }\end{array}$ & $\begin{array}{l}\text { Activity } \\
\text { monitor }\end{array}$ & $\begin{array}{l}\text { Safety } \\
\text { monitor }\end{array}$ & $\begin{array}{l}\text { Medication } \\
\text { monitor }\end{array}$ \\
\hline $\begin{array}{l}\text { Weight } \\
\text { measurement } \\
\text { Blood } \\
\text { Pressure } \\
\text { measurement } \\
\text { ECG } \\
\text { Blood } \\
\text { Glucose } \\
\text { Measurement } \\
\text { Heart Rate } \\
\text { Measurement }\end{array}$ & $\begin{array}{l}\text { Walking time } \\
\text { Measurement } \\
\text { Step } \\
\text { Counting } \\
\text { Speed } \\
\text { Measurement } \\
\text { Calorie } \\
\text { Spent } \\
\text { Time Spent }\end{array}$ & $\begin{array}{l}\text { Fall } \\
\text { Detection } \\
\text { Personal } \\
\text { Safety } \\
\text { Device }\end{array}$ & $\begin{array}{l}\text { Medication } \\
\text { adherence } \\
\text { system } \\
\text { Smart pill } \\
\text { dispenser }\end{array}$ \\
\hline
\end{tabular}

In the proposed system peripheral area network is also utilized. The peripheral area network will use the gateway as an aggregate method which will collect and transfer the parameters collected to the cloud. The cloud contains the database from where these parameters are checked against the disease database. Matching parameter percentage will indicate the infection rate and possible cures.

The healthcare information will be shifted to the cloud in the proposed paper. Legion of advantages exists when healthcare data is shifted to the cloud. The mobile user can take advantage of the system which is stored in the cloud. The user inputs the parameters into the proposed system and results will be generated right at the mobile user device. So the user does not have to go to the hospitals for diagnosis.The advantages are listed in terms of the following table.

TABLE II

Showing incentives for the cloud computing

\begin{tabular}{|l|l|}
\hline Parameters & Description \\
\hline Collaboration & $\begin{array}{l}\text { Use of cloud facilitates the } \\
\text { sharing of information }\end{array}$ \\
\hline
\end{tabular}




\begin{tabular}{|l|l|}
\hline & $\begin{array}{l}\text { among the physicians, } \\
\text { health agencies and } \\
\text { government officials. }\end{array}$ \\
\hline Rapidity & $\begin{array}{l}\text { Cloud provides system } \\
\text { through which data will } \\
\text { travel quickly towards the } \\
\text { destination }\end{array}$ \\
\hline Mobility & $\begin{array}{l}\text { User can get the } \\
\text { information right at his/her } \\
\text { place without moving an } \\
\text { inch }\end{array}$ \\
\hline Reduced costs & $\begin{array}{l}\text { User will pay for the } \\
\text { resources they utilize and } \\
\text { nothing else }\end{array}$ \\
\hline Large storage space & $\begin{array}{l}\text { Cloud provides a large } \\
\text { amount of space, and hence } \\
\text { a large amount of data can } \\
\text { be stored without loss of } \\
\text { previous data. }\end{array}$ \\
\hline
\end{tabular}

To make the outbreak to be restraint government should provide checking for every user. This is not possible under normal circumstances. So the proposed system should provide the following

- To provide the users with the initial diagnosis of the disease based on the symptoms presented.

- To determine the infected population.

- To provide secure storage for records stored in the cloud.

The data mining tools can be used in order to analyze the data which is stored in the cloud. The government can take necessary steps to slow the rate of disease rift. The proposed system will judge the matter efficiently.

The proposed paper is divided into sections. The first section describes the literature survey in the form of related work; the second section describes the proposed system and proposed model, the third section describes results and conclusion and last section describes the concept of references.

In the proposed paper the analysis of various types of HIV virus will be constructed. Along with that, the proposed system will also detect the infected persons using internet of things and also suggest the improvement using evidencebased medicine system.

\section{RELATED WORK}

In the area of healthcare through IoT work has been done. The source identification and transmission of the virus from source to the destination is important in order to slow the rate of HIV rift. Detection and prevention are important in this case. This section is divided into following subparts.

A. IoT

The internet of thing provide a mechanism in order to judge health care system effectually[1] which include Smart City, providing health-care facilities efficiently is a great issue. Developing nations lessen proportionate health-care delivery answers to judge huge population. To judge the ever increased population, answers for delivering health-care should be better. A possible solution is to use present information \& communication system to providing remote health-care. Internet of Things (IoT) is seen as enabling technology to judge this purpose. We proposed a SensorCloud prototype aiming at proper delivery of the health-care services. During implementation, we feel the problems of resource-constrained health sensors. In my Ph.D., I judge questions like how to collaborate various health sensors with cloud without much problem, how to collect health data from wireless bio-medical sensors, how to judge patient mobility and what will be appropriate routing scheme within this IoT enabled prototype. [2]Recently, cloud computing and Internet of Things (IoT) have constructed their entrance in the pervasive healthcare field in smart city supra system. However, the integration of IoTs and cloud computing in healthcare domain implement several technical problems that have not yet received full attention from the analysis community. Some of these problems are reliable transmission of important sign data to cloud, dynamic resource assigned to facilitate seamless access and processing of IoT data, and effectual data mining techniques. In this paper, we propose a prototype to address above challenging issues. In addition, we discuss the possible answers to tackle some of these problems in smart city supra system.[3]Despite the fact that the concept of using long-term personal records has been well recognized for decades, sparse patient physical exam records are still the main base for disease diagnosis and improvement. One of the main causes for this is the lessen of instruments and systems for effectually collecting real-time personal data and turning the data into health-meaningful information. The current evolution of wearable instruments with IoT presents a huge potential for fulfilling the needs of longterm data collecting and enabling patients to be checked in real-time. Wearable important sign measuring instruments with IoT enable the elderly with chronic diseases to be checked, connected to healthcare providers and offered improvement at the right moment. Smart drug dispensers provide automatic reminders and medication recording capability for better improvement. There is a lot more which can be achieved through the adoption of IoT and wearable instruments.Looking at recent evolutions in wearable instruments and IoT, we can expect a fast surge in applications in the upcoming years. However, its general adoption in healthcare is going to take a larger time. In this talk, we will give an overview of the evolution of wearable instruments and IoT for healthcare applications and discuss their impacts on reshaping healthcare. Several examples will be given from different perspectives. Factors which affect the acceptance and widespread use of wearable instruments and IoT in healthcare will also be discussed. If this talk can judge as a facilitator for the invention of a widely-adopted device or system for the benefit of healthcare, it will have achieved its purpose.[4]This the paper proposes the Internet of Things communication prototype as the main enabler for distributed worldwide healthcare applications. Starting from the recent availability of wireless medical sensor prototypes and the growing dispersal of electronic healthcare record databases, we analyze the requirements of a unified communication prototype. Our investigation takes the move by decomposing the storyline of a day in Robert's life, our unlucky character in the not so long future, into simple processes and their interactions. Subsequently, we devise the main communication requirements for those processes and for their integration on the Internet as web services. Finally, we present the Internet of Things protocol stack and the advantages it brings to health care scenarios in terms of the identified requirements.[5]The Internet of Things (IoT) 
makes smart objects the ultimate building blocks in the evolution of cyber-physical smart pervasive prototypes. The IoT has a variety of application domains, including health care. The IoT revolution is redesigning modern health care with promising technological, economic, and social prospects. This paper surveys approach in IoT-based health care system and reviews the state-of-the-art network architectures/platforms, applications, and industry trends in IoT-based health care answers. In addition, this paper analyzes distinct IoT security and privacy features, including security requirements, threat models, and attack taxonomies from the healthcare perspective. Further, this paper proposes an intelligent collaborative security model to minimize security danger; discusses how different innovations such as great data, ambient intelligence, and wearables can be leveraged in a healthcare context; addresses various IoT and eHealth policies and regulations across the world to determine how they can facilitate economies and societies in terms of sustainable evolution; and provides some avenues for future analysis on IoT-based health care based on a set of open issues and problems.

\section{B. HIV Handling}

[6]The paper suggests a portable molecular diagnostic tool presented by CMOS and Microfluidic technique for early HIV diagnosis.

From the above papers, we have analyzed that the work has been done toward the diseases other than HIV virus. So in the proposed paper, we will work on this virus and suggest the mechanism to judge this virus.

\section{PROPOSED SYSTEM}

The proposed work deals with the detection of the persons who are infected with HIV. This is the disease which cannot be cured, but rather its rate could be slow down by the use of certain medicines.

For HIV transmission to happen, four conditions need to be present:

- Presence: Virus has to be present, first of all in the body of an infected person, and secondly in that person's body fluid or tissue to which another person is exposed.

- Quantity: There has to be a sufficient amount of the virus in the body fluid through which the infection is conveyed. (Infectious virus may be present either as 'free' virus or as viral DNA 'hidden' within infected cells.

- Route: Virus has to get into the body of the uninfected person through an effectual route.

- Susceptibility: Finally, cells which are susceptible to infection must be present at the site of entry, and host defenses must be inadequate to prevent infection.

This deadly disease could not be cured, but it is possible to identify the persons who are infected and taken good care to avoid further expansion of this disease by the use of the proposed model. The concept of sensors is also used in this case. The sensors will monitor the location of the persons who are infected with this virus. The tracking of those persons is constructed with the help of GPS. The middleware will be required in order to monitor the health of the patient.

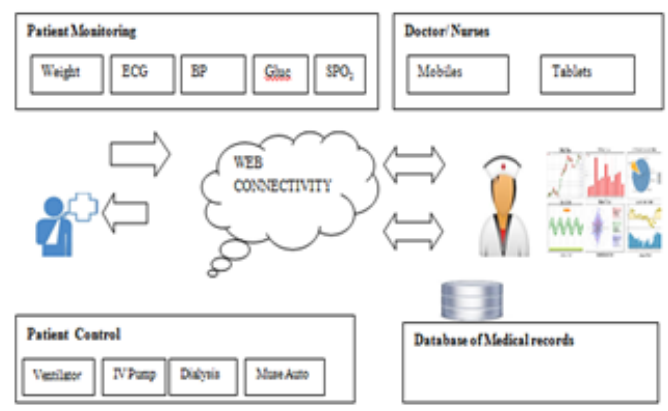

Fig.1 Showing the Cloud system for Detecting and preventing $\mathrm{HIV}$

The proposed model keeps monitoring the patient characteristics to determine the status of their health. Various parameters which are analyzed will include weight, ECG, BP, Glucose, etc. The details of the patients are transmitted to the doctor/nurses. The sensors help to transform the physical world data (e.g., temperature, pressure, humidity, etc.) including human health data (heart rate, oxygen saturation, blood pressure, blood glucose, etc.) to the digital world and the actuators transforms the digital data into physical actions (e.g.: Infusion pumps, dialysis system, etc.). The IoT instruments have sensors for receiving signals from the supra-system for analysis, or actuators for controlling the supra-system based on the inputs, or both sensors and actuators.

The flow of information is shown in Fig 2. The system begins when a user registers him/her self-using mobile application or website. After registration is complete, a unique ID number is provided by the system, and the data table is truncated using information granulation approach for securing the identity of the user. BBN is applied to analyze information transferred by the user to determine him/her into uninfected and possibly infected user. The possibly infected user is the category where the initial determination of the proposed system divided the user as infected but not confirmed.

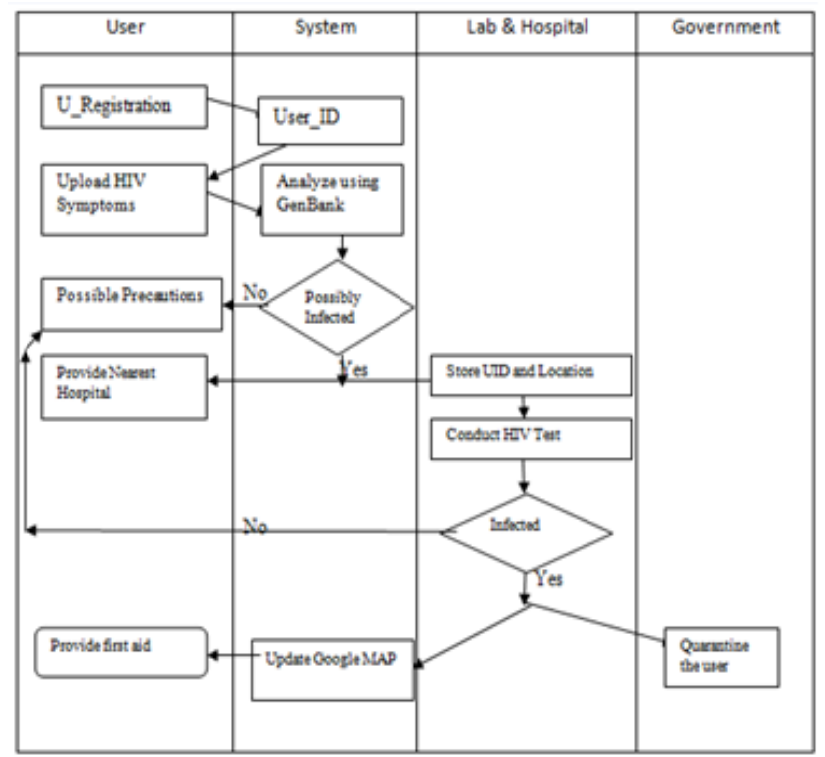

Fig.2 Showing flow of information through system

The proposed model will go to locate the persons who have the problems and if they are not suffering from HIV then related diseases which have some related attributes. For this 
purpose, the database will be maintained. The database will contain the attributes of the diseases. The person having a disease and matched attributes will be cautioned, and suggestion to cure the disease will be constructed. The proposed system has a number of stages associated with them.

\section{A. Data Collection}

In order to detect the problems detect the presence of HIV virus within humans sensor nodes are required. The data collection is used for this purpose. The collection of data which we use is derived from Gen Bank dataset. The dataset describes the collection in terms of types of HIV which is commonly present in the humans. The proposed work will use this dataset to derive different conclusions about the disease which is deadly in nature. Various attributes present and used within the proposed system includes:

\section{TABLE III}

Health attributes of user for HIV

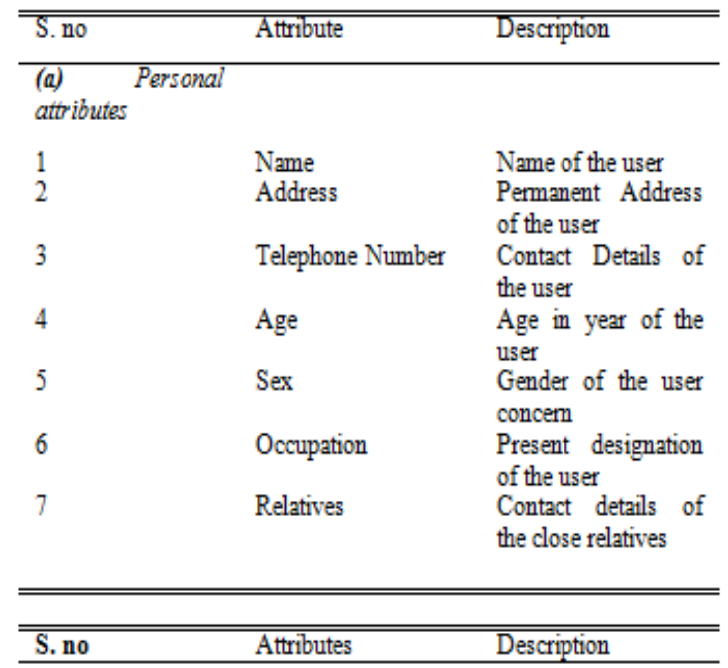

\begin{tabular}{lll}
$\begin{array}{l}\text { (b) HIV related } \\
\text { attibutes } \\
\mathbf{1}\end{array}$ & Fever & $\begin{array}{l}\text { A body temperature } \\
\text { in Centigrade }\end{array}$ \\
$\mathbf{2}$ & Severe Fatigue & $\begin{array}{l}\text { Extreme tiredness } \\
\mathbf{3}\end{array}$ \\
$\mathbf{A}$ & A non-itchy rash & $\begin{array}{l}\text { Noticeable change } \\
\text { in texture of the skin }\end{array}$ \\
$\mathbf{5}$ & Sore throat & $\begin{array}{l}\text { Pain in the throat } \\
\text { A user has cough } \\
\text { Symptoms }\end{array}$ \\
\hline \hline
\end{tabular}

\section{B. Secure transmission of data}

The information which is to be transmitted over the network must be secured in nature. Some information may be such that it should not be disclosed. This is the reason for which secure transfer of information is compulsory. The secure transmission of information can be achieved with the help of encryption. The RSA algorithm can be used in order to encrypt the information transmitted over the network. An initial data table containing all information is fragmented into three separate data matrices of different security levels: Level 1 (personal information), Level 2(demographic information), and Level 3 information. Level 1 is highly sensitive information containing personal attributes such as name, social security number (SSN), address, and mobile number. Level 2 is the mediocre level of information containing demographic attributes such as gender, race, height, and ethnicity. Level 3 is least sensitive information containing HIV attributes and symptoms. Even if anyone could retrieve Level 3 information because it is maintained at the least secure system, the person will not be able to find an exact identity of the user. For retrieving the exact identity of the user, a person requires the knowledge of all three levels of matrices.

In the proposed system we will work on the level 1 of the information. This kind of information is most sensitive and has to be secured for the unauthorized access.

\section{Genbank based data analysis}

The Gen Bank provides the dataset associated with the HIV and its different subtypes. The HIV virus can be of POL type which will be predicted with the help of the GEN BANK dataset and plotted through the MATLAB plot function. The hierarchical structure is listed using the proposed technique.

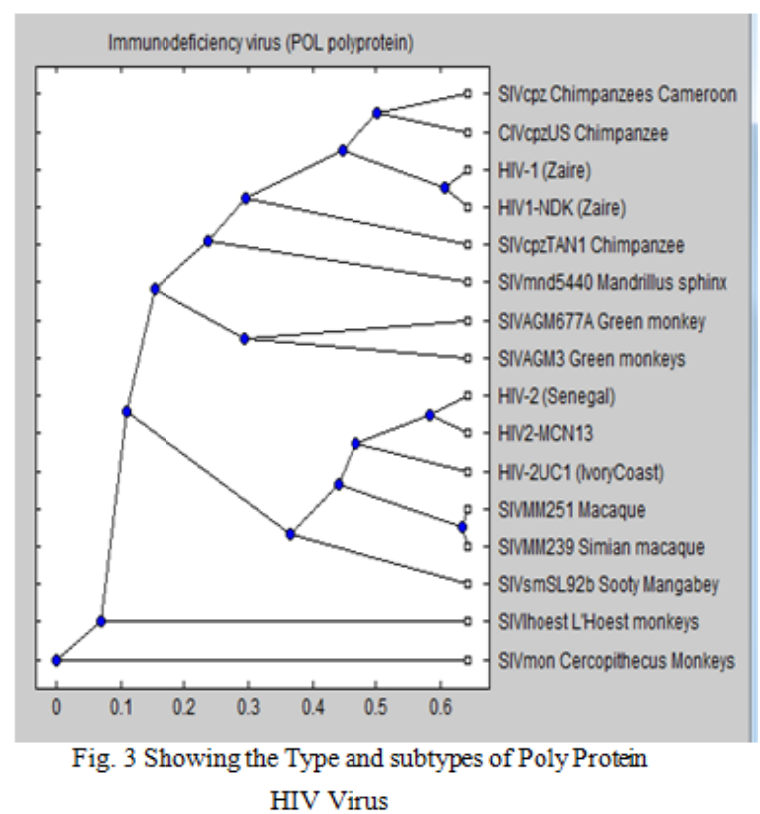

The information related to HIV has to extend among the population so that people become aware of it and better cure can be devised. The dataset served a great purpose in this regard. The GEN bank dataset is again plotted for ENV HIV virus, and the information is listed in the tree structure and analyzed from root to child.

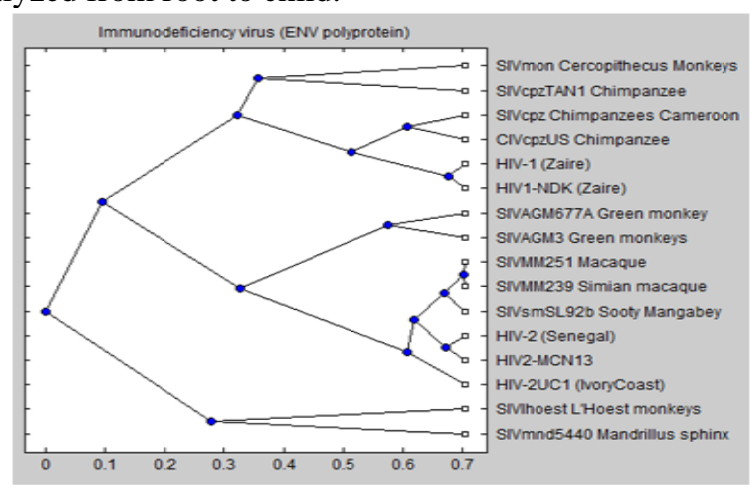

Fig. 4 Showing the Type and subtypes of ENV Poly Protein HIV Virus 


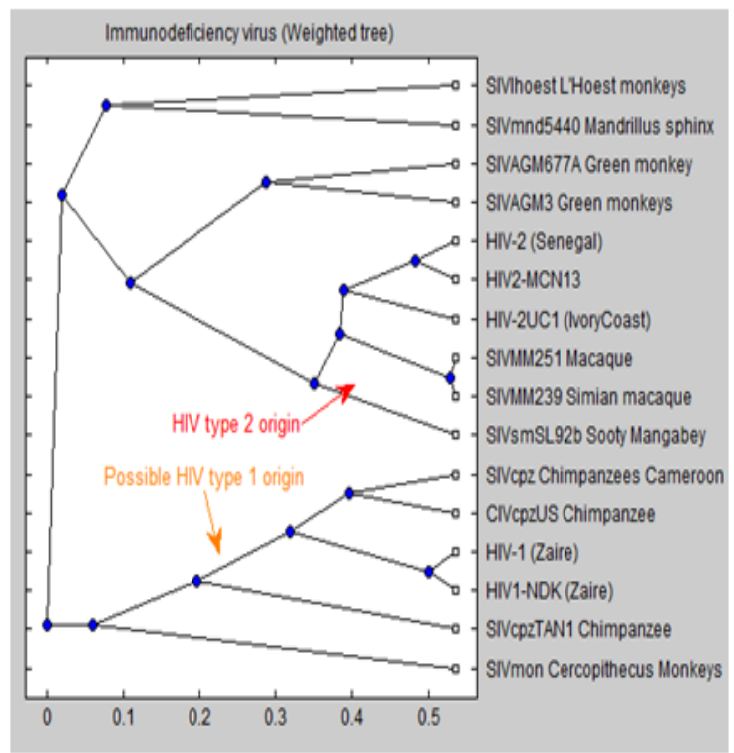

Fig. 5 Showing the Type 1 and Type 2 HIV Virus

\section{GPS based risk assessment}

The Geographical Positioning system is used in order to give the direction to the user. The same mechanism can be used in order to locate the persons who are infected with the disease. This can be used in order to analyze the Risk associated with this deadly disease. The proposer up to date information helps in alerting the users living in the same area and hence stops further spreading of such disease. Different color schemes are used in order to plot the position of the area which is most infected. The plotting will take place over the map. The internet connection will be required in order to plot the position and use google map. The risk of the infected person spreading the disease will be minimized if the accurate position of the infected person is known. This is accomplished by the use of the proposed system.

The density of the infection in different regions will be given in terms of the percentage(\%). The plotted areas within the graph indicate the most infected area. The persons present within that region can be made aware of the situation, and spread of the disease can be neutralized. The proposed system is automatically updated with time as new cases arrived and possibly infected users are tested. Algorithm 2 will be triggered by only authorized medical officers using highly secure biometric.

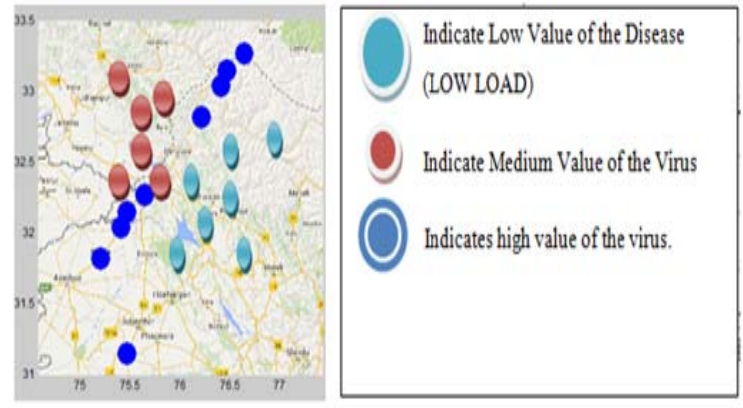

Fig. 6 Shoring the HIV incidence and prevalence

The algorithm describing the GPS based infection detection and updating is described as

Algorithm 1: identifying areas

Step 1: Make user input the id

Step 2: Verify the Id and check the blood sample
Step 3: if(Positive)

3.1 Quarantine the user and inform the relatives

3.2 Update location of the user on the map

Else

3.3Inform the user and suggest precautions End of if

Step 4: Stop

The algorithm will take the user input and verify the details of the user to determine whether the user is infected or not. The location of the user has to update on the map if the user is infected. The same information will be propagated to the family members also. The user if not infected then precautions are suggested.

\section{IV.DISCUSSION OF RESULTS}

The following graph shows the rate of growth of the HIV infected persons

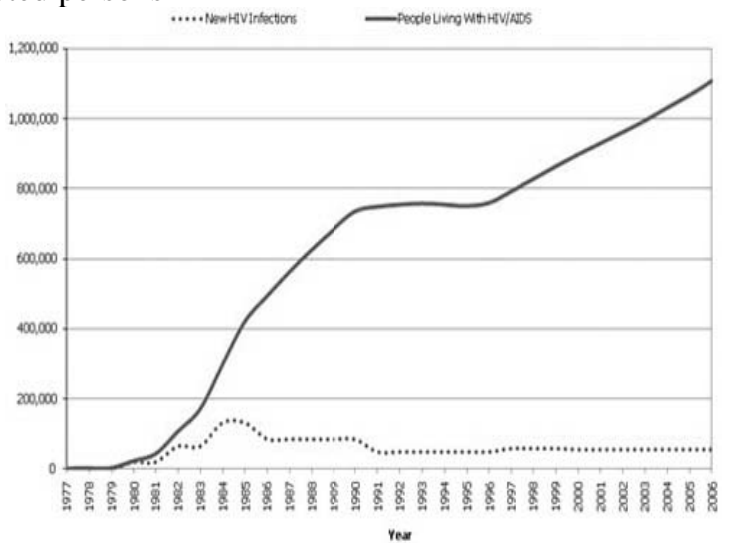

Fig.7 Showing the HIV incidence and prevalence

The HIV testing is generated through the proposed model is given through a table.

TABLE IV

Showing the reading of the various clinics about HIV

\begin{tabular}{ll}
\hline \hline $\begin{array}{l}\text { Health Care System Supported } \\
\text { by routine HIV Testing }\end{array}$ & $\%$ Respondent $(\mathrm{n}=43$ ) \\
\hline \hline STDCLINICS & $79 \%$ \\
$\begin{array}{l}\text { HOSPITAL EMERGENCY } \\
\text { DEPARTMENTS }\end{array}$ & $60 \%$ \\
$\begin{array}{l}\text { COMMUNITY HEALTH } \\
\text { CLINICS }\end{array}$ & $60 \%$ \\
CORRECIONS & $51 \%$ \\
FAMILY PLANNING & $51 \%$ \\
CLINICS & $51 \%$ \\
TB CLINICS & $42 \%$ \\
PRENTAL CLINICS & $35 \%$ \\
PRIMARY CLINICS & $35 \%$ \\
URGENT CARE & $28 \%$ \\
LABOUR AND DELIVERY & $19 \%$ \\
OTHERS &
\end{tabular}

The reading of the virus has been taken from the clinics and fed into the database of healthcare maintained under the 
proposed model. When the same reading is taken with the proposed model, then the adjudged cases are increased by $10 \%$ in lesser time.

\section{V.CONCLUSION}

The proposed model detects the persons infected with the HIV. The dataset of GENBANK is used. This dataset is online in nature. The proposed model indicates that the rate of detection is much higher as compared to the previous work. In order to use the proposed system Internet is required. Also, the cloud is used in order to store the database of HIV characteristics. The patients will feed the attributes values within the model and result will be produced and given to the user on their mobile instruments.

\section{REFERENCES}

[1] S. Sankar Bhunia, "Adopting internet of things for providing health-care," in Proceedings of the 2015 ACM International Joint Conference on Pervasive and Ubiquitous Computing and Proceedings of the 2015 ACM International Symposium on Wearable Computers - UbiComp '15, 2015, pp. 533-538.

[2] M. M. Hassan, H. S. Albakr, and H. Al-Dossari, "A Cloud-
Assisted Internet of Things Prototype for Pervasive Healthcare in Smart City Supra system," in Proceedings of the 1st International Workshop on Emerging Multimedia Applications and Services for Smart Cities - EMAC '14, 2014, pp. 9-13.

[3] P.-C. J. Chung, "Impacts of IoT and Wearable Instruments on Healthcare," in Proceedings of the 12th International Conference on Approach in Mobile Computing and Multimedia - MoMM '14, 2014, pp. 2-2.

[4] N. Bui and M. Zorzi, "Healthcare applications," in Proceedings of the 4th International Symposium on Applied Sciences in Biomedical and Communication System ISABEL '11, 2011, pp. 1-5.

[5] S. M. Riazul Islam, M. Humayun Kabir, and M. Hossain, "The Internet of Things for Health Care: A Comprehensive Survey,” IEEE Access, vol. 3, pp. 678-708, 2015.

[6] M. E. Zaghloul, "Point-of-care early HIV diagnosis system on the CMOS \& microfluidic hybrid platform," in Proceedings of 2012 IEEE-EMBS International Conference on Biomedical and Health Informatics, 2012, pp. 624-627.

[7] A. V. Ganesan, D. Kishore Kumar, A. Banerjee, and S. Swaminathan, "MEMS-based microfluidic system for HIV detection," in 2013 13th IEEE International Conference on Nanotechnology (IEEE-NANO 2013), 2013, pp. 557-560. 